In the one illustrative case mentioned this professor adinitted that he often changed his treatment daily, though he gave no reason, and at least two out of three of the medicinal articles mentioned were secret proprietary goods. He was clearly trying to sail his ship without a chart, veering with every shift of the wind.

In the discussion, one speaker mentioned the fact that physicians had long enough been used by manufacturers as advertis. ing agents without pay, and the more doctors use secret mixtures the less exact they become. He was immediately followed by a member who said in substance: "The true physician, when he looks on the sufferings of a helpless child, rises above the narrow limitations of ethical laws and takes aid whereever he can find it." He added that the "patent medicine" mentioned gave relief in such cases, but even he did not claim that this "patent medicine" was the only thing that might help. One after another of those present spoke in favor of that particular secret mixture. Some used it because it was "put up in convenient shape." Not one could tell of what it was composed, nor give any reason for its superiority.

I was surprised that the remarks on "ethics" called forth applause. Rules of ethics are not arbitrary laws, but deductions of those who have studied the subject. Webster calls ethics: "The science of human duty," and that is as good a definition as we need. Clearly the rules of ethics, whether written or not, demand of the physician or surgeon the most speedy relief possible. They demand that he shall use his best skill. He has no right to use something simply because it is "handy" and saves thinking. He must know.

But think of the effect on the spectators when the learned doctor without a struggle uses a secret mixture, the qualities of which each of them know as well as he-from the advertisements!

The remark about a "suffering child" is good oratory, but it was made in a surgical discussion. Suppose the child had been gored by a bull. Would the doctor sanction the relief of suffering by the replacement of the intestines by the dirty hands of a stable boy? Certainly not, for fear of adding an unknown infection or poison.

In the use of the secret mixture is he sure that he is not adding an unsuspected poison? Is he not blindly following empirical charlatanry?

The professor closed the discussion somewhat as follows: "I used the secret mixture mentioned because the professor of internal medicine in one of our leading colleges, suggested it. If I did wrong, he did wrong. He got me to use it." Such childish evasion of responsibility by a college professor is a disgrace. The really alarming feature is not that a secret drug was used, but that men who should be leaders do not recognize that surh an act is a public confession of their ab. solute incompetence, and to that degree it stamps them with the mark of quackery.

Henry B. Hemenway.

\section{Vocal Fremitus in Pleural Effusions.}

Philadelphia, Jan. 25, 1908

T'o the Editor:-In The Journal, Dec, 7, 1907 , appears an interesting and valuable note by Dr. W. J. Calvert on "Increased Vocal Fremitus in Pleural Effusions. The increase or persistence of the voice vibrations is, as Dr. Calvert states, most unusual in the effusions of adults; but it does not seem to be generally appreciated that in infants and young children this phenomenon occurs with comparative frequency. I have repeatedly satisfied myself of this and have demonstrated it to, and have had my observation confirmed by internes at the Children's Hospital, Philadelphia.

The character of the fremitus, while it constitutes one of the most valuable means of diagnosis of pleural effusions, I have come to regard as unreliable in young children, because $I$ have found it so variable: unchanged, retained or even increased. This fact, together with the frequency of bronchial breathing and voice over the fluid, has led to many mistakes in diagnosis.

In making these remarks, I am not alluding to the increased fremitus present in all large effusions beneath the clavicle and in the inner scapular region, and due to the com- pressed lung; but to a fremitus observed lower down over the effused fluid itself.

I know of no American pediatric writer who mentions the phenomenon now under discussion; but it has frequently leen commented on by English authors (Eustace Smith among others). The explanation given by Dr. Calvert that increased fremitus in pleural effusions is due, in most instances, to intrathoracic tension is probably correct; but it will not account for its comparative frequency in infancy and childhood.

D. J. Milton Miller.

\section{Carbon Dioxid Not Cause of Death Following Use of Antitoxin.} BEDFord, Ind., Jan. 21, 1908.

To the Editor:-In The Jocrisal, January 18, Dr. Lewis M. Gainer of Wake Forest, N. C., commenting on a death from diphtheria antitoxin, suggests that the excess of carbon dioxid in the blood may have produced an irritability of the respiratory center's and that the antitoxin may have added to that irritability and produced death. In laryngeal diphtheria a marked cyanosis is often seen, due to lack of oxygen and excess of carbon dioxid; in these cases it is my rule to give from 5.000 to 8.000 units of antitoxin for an snitial dose in any child from 3 to 8 years old. I have never seen any untoward results even when the dyspnea and cyanosis were extremely marked. The thought came to me that there must have been some other cause for death in this case. Physicians should never hesitate to give large doses of antitoxin in laryngeal diphtheria; the greater the eyanosis the larger tho dosage.

C. H. Emery, M.D.

\section{Book Notices}

Royal Commissiox on Vinsection. Appendix to the Third Report of the Commissioners. Minuies of Evidence, April to July 1007. Y'p. vi-266. I'rice, 2s. 2d. London: Wyman \& Sons, Limited, 109 Fetter Lane, E. C., 1907 .

This volume contains the testimony of a number of prominent physiologists and others on both sides of the question. Besides the representatives of the antivivsection societies at whose instance the commission took up the subject, we have here the utterances on the subject of slich authorities as Sir T. Lauder Brunton, Mr. Henry Morris. F.R.C.S., Major Rogers of the Medical College of Calcutta, Sir H. R. Swanzy, Prof. E. A. Schäfer, Dr. C. J. Martin and Dr. D. W. Buxton, lecturer on anesthetics in the University College Hospital of London. Drs. Brunton, Morris, Rogers, Swanzy and Schäfer review the history of physiologic progress, showing how much of it is due to animal experimentation and how the older investigators in this line, like Hales, Bell. and later Claude Bernard and others, laid down the foundations by experiments on animals on which our modern knowledge of physiology is based. Mr. Henry Morris gives a diagram, showing how lister's early work on infammation, etc., and that of Pasteur led up to Lister's work on the treatment of wounds, from which has branched off the seience of bacteriology on the one hand, with all its medical bearings and the possibilities of modern operative surgery on the other, neither of which would have been possible without the knowlelge obtained by animal experimentation. Thus the causes of the various infectious diseases conld never have been discovered in any other way, and the facts we possess in regard to immunity and serum therapy could only have been obtained in this way, to say nothing of the advances in diagnosis, knowledge of the life history of pathogenic germs, which is absolutely necessary to our ability to resist them, and ail the hygienic and surgical improvements which have made commonplaces in our day of life-saving and pain-saving operations never before thought of. Morris gives a partial list of diseases (including diphtheria, tetanus, hydrophobia, anthrax, glanders and exophthalmic goiter) our power to cure, prevent or relieve which is directly dependent on animal experimentation, and he quotes also the researches now being made on cancer as giving a hope for still further progress in this direction. Major Rogers of the Indian Medical Service gives an account of the work already done in regard to the cure of snake bites and the control of rinderpest in 